\title{
Urine Calcium Measurement
}

National Cancer Institute

\section{Source}

National Cancer Institute. Urine Calcium Measurement. NCI Thesaurus. Code C61046.

A quantitative measurement of the total amount of calcium present in a sample of urine. 